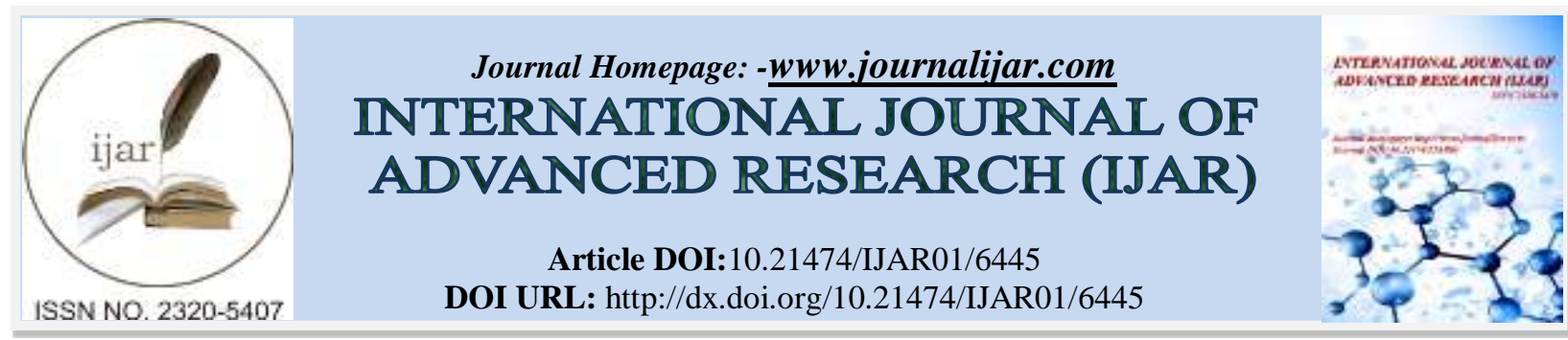

RESEARCH ARTICLE

\title{
GLYCEMIC CONTROL IN PEOPLE WITH TYPE 2 DIABETES COMMENCING OR ADJUSTING INSULIN TREATMENT IN CLINICAL PRACTICE: A MULTINATIONAL, MULTICENTER, OBSERVATIONAL COHORT STUDY IN THE GULF REGION.
}

1. Spital, United Arab Emirates.

\section{Rashid Ho Khadija ${ }^{1}$, Ahmed Hafidh ${ }^{1}$ and Salah Abusnana ${ }^{2}$.}

2. RCDR-Khalifa Hospital, United Arab Emirates.

\section{Manuscript Info}

Manuscript History

Received: 04 December 2017

Final Accepted: 06 January 2018

Published: February 2018

\section{Keywords:-}

Observational study, type 2 diabetes, Gulf region, basal insulin, prandial insulin.

\section{Abstract}

Type 2 diabetes mellitus (T2DM) is prevalent in the Middle East and North Africa as a consequence of increasing aging populations, rapid urbanization, lack of physical exercise, and obesity. Our study objective is to explore glycemic outcomes in people with T2DM patients who initiated basal insulin treatment or who received a further adjustment of existing insulin treatment. Multinational, multicenter, non-interventional study was conducted in the Gulf region. The primary objective was to assess $\mathrm{HbA1c}$ reduction from baseline, to three and six months following treatment with insulin-based regimens. Secondary outcomes included the percentage of patients achieving the $\mathrm{HbA} 1 \mathrm{c}$ target of $<7.0 \%$ at 6 months, change in fasting, and postprandial blood glucose, insulin dose, body weight, the incidence of hypoglycemia, and patient characteristics associated with the success of glycemic control.

Overall, 1196 patients from 102 centers were recruited and 1083 received a basal insulin-based therapy for six-months. Mean (SD) baseline characteristics were: age $56.2 \pm 12$ years, weight $82.7 \pm 14.9$ $\mathrm{kg}$, BMI $29.8 \pm 5.2 \mathrm{~kg} / \mathrm{m}^{2}$, diabetes duration $11 \pm 6.9$ years, and $55 \%$ were male. Initiation or adjustment of basal insulin reduced mean $\mathrm{HbA1c}$ from $9.8 \% \pm 1.6 \%$ to $7.6 \% \pm 1 \%$ and mean FBG from $208.1 \pm$ $70 \mathrm{mg} / \mathrm{dl}$ to $128.6 \pm 32.3 \mathrm{mg} / \mathrm{dl}$. At 6 months, $25.9 \%$ of patients achieved target HbA1c $<7.0 \%$. Predictors of glycemic control (HbA1c $<7 \%)$ included age $(\mathrm{OR}=1.01 ; \mathrm{p}=0.043)$, baseline HbA1c $(\mathrm{OR}=$ $0.68 ; \mathrm{p}<0.001)$, BMI $(\mathrm{OR}=0.96 ; \mathrm{p}=0.012)$, and exercise $(\mathrm{OR}=1.5$; $\mathrm{p}=0.036$ ). Incidence of hypoglycemia was $5.3 \%$, and no significant change in body weight was observed $(p=0.074)$. In conclusion, Basal insulin treatment with or without addition of prandial insulin is an efficacious and well tolerated regimen for T2DM patients from the Gulf regions inadequately controlled with oral antidiabetic drugs. 


\section{Introduction:-}

Diabetes mellitus (DM) is a serious and complex chronic disorder, accounting for 55.8 million disability-adjusted life years in 2013 (Murray et al., 2015). During the last three decades, the incidence of DM has increased almost 4fold; this metabolic disorder affects over 420 million individuals globally, most of whom are diagnosed with type- 2 diabetes (T2D) (WHO, 2016). Based on current projections, DM is set to become the $7^{\text {th }}$ leading cause of mortality by the year 2030, highlighting the urgent need to develop improved treatment, management, and preventive strategies (Wild et al., 2004).

While DM is a global disease, countries in the Middle East and North Africa are among the most heavily affected by this disorder (Majeed et al., 2014, Zabetian et al., 2013). Saudi Arabia, Bahrain, Qatar and Kuwait all feature in the top 10 countries worldwide for the prevalence of T2D, and ageing populations, urbanization, increasingly sedentary lifestyles, and obesity are accountable for this epidemic. The incidence of T2D is projected to double by 2035 (Majeed et al., 2014). This is a major concern for Arab countries considering the substantial economic burden of this disease, as well as the potential impact on societies and healthcare systems.

T2D encompasses individuals with insulin resistance and progressive $\beta$-cell dysfunction (DeFronzo, 1997). The resulting glycemic imbalance is a precursor for macrovascular and microvascular complications including cardiovascular difficulties, stroke, peripheral vascular disease, diabetic neuropathies, nephropathies, and retinopathies. The primary goal of antidiabetic therapies is to re-establish glycemic homeostasis; reduction of glycated hemoglobin (HbA1c) scores by a single point significantly reduces the risk of diabetes-related complications (Stratton et al., 2000). For patients with a confirmed T2D diagnosis and an HbA1c < 9\%, the ADA recommends first-line treatment with oral antidiabetics (OADs) (American Diabetes association, 2017). Given the progressive nature of $\beta$-cell dysfunction in T2D, OADs are often incapable of sufficiently maintaining acceptable HbA1c levels; approximately $60 \%$ of patients will require - within 6-10 years of diagnosis - an OAD/insulin combination therapy to maintain normoglycemia (Hammaty, 2011, Pearson and Powers, 2006). Insulin-based therapies may include basal insulin, a basal plus strategy, or premixed insulin products.

This observational product registry was conducted to investigate improvements in glycemic control in T2D patients residing in the Gulf regions, and for whom insulin-based regimens is initiated or adjusted to improve HbA1c. The primary objective was to assess the mean change in HbA1c following six months of therapy. Secondary objectives included evaluating the proportion of patients achieving the recommended HbA1c target of $<7 \%$, identifying factors that are predictive of treatment outcomes, assessing changes in insulin dose and weight, and to determine the incidence of hypoglycaemia associated with such treatments.

\section{Materials and methods:- Study objectives:-}

The primary objective of this study was to assess the extent of HbA1c reduction at six months among T2D patients for whom basal insulin \pm prandial insulin was prescribed in a clinical setting at the full discretion of the treating physician. The secondary objectives of this study were to 1) identify predictive factors for the achievement of glycemic control (HbA1c $<7 \%$ ) in T2D patients; 2) determine the percentage of patients achieving the recommended HbA1c target $(<7 \%)$ following the administration of a six-month insulin-based treatment regimen; 3 ) assess the change in the prescribed insulin doses from baseline to six months; 4) assess the weight changes of the enrolled participants following treatment; and 5) assess the incidence of AEs during the observational period, including the frequency of symptomatic hypoglycemia.

\section{Study design:-}

This non-interventional, non-controlled, non-comparative, prospective observational study was conducted in 102 centers from Lebanon, United Arab Emirates (UAE), Kuwait, Qatar, and Bahrain. Inadequately controlled T2D patients, for whom adjunct insulin therapy with basal insulin or an adjustment to previous therapy (either basal or pre-mixed insulin) was prescribed, as per physician discretion, were enrolled.

In a previous report by Sharplin et al. (2009), a mean HbA1c reduction of $0.47 \%$ was demonstrated for patients switching to insulin glargine-based regimens. We anticipated a similar reduction in HbA1c with a two-sided 5\% significance level and a power of $99.5 \%$. We aimed to enroll 1300 patients, considering a target sample size of 1170 , 
and an anticipated drop-out rate of 10\%. Recruitment of subjects spanned a duration of 16 months during which participating centers recruited eligible patients in a consecutive fashion to limit patient selection bias.

\section{Patient population:-}

Type 2 Diabetes subjects included male and female adults over the age of 18 years. Subjects were required to meet the following criteria to be deemed eligible for study participation: 1) a willingness to provide written informed consent prior to study entry; 2) demonstrate inadequate glycemic control, with an HbAlc $\geq 7 \%$; 3) adjunct therapy with basal insulin or an adjustment of prior insulin therapy (either basal or pre-mixed insulins) was prescribed at investigators' discretion. Exclusion criteria included insulin glargine and insulin glulisine hypersensitivity, brittle diabetes, psychiatric or mental illness, inability or unwillingness to manage and adjust insulin regimens, and participation in other clinical research trials. Furthermore, pregnant and breastfeeding females were ineligible for participation.

\section{Treatments:-}

All participating subjects were prescribed basal insulin with or without prandial insulin, independent of the decision to participate in the current investigation. All antidiabetic treatment-related decisions were under the sole discretion of the participating investigators. This included the decision to initiate a basal insulin regimen or modify previous insulin therapies. Investigators were guided by summary of product characteristics $(\mathrm{SmPc})$ for information and treatment recommendations.

\section{Data collection:-}

The current study was purely observational in nature. This design allowed for an investigation of the effectiveness of insulin-based therapies in "real-world" clinical settings. As such, we adopted a flexible study schedule; study visits were conducted in a manner that was consistent with routine clinical practice and additional assessments or procedures that deviate from routine practice were not imposed. A baseline assessment (visit 1) was conducted for all enrolled subjects once eligibility was confirmed. During this first study visit, participants were subjected to a physical examination. Demographical and socioeconomic data, medical and treatment history, vital signs, blood glucose levels (fasting and postprandial), and prior involvement in diabetes educational programs were among the data collected. The incidence of adverse events (including the number of both documented and symptomatic hypoglycemic episodes), and changes in FPG, PPG, HbAlc, and antidiabetic treatment regimens were assessed during the three- and six-month follow up visits (visit 2 and 3 , respectively).

\section{Safety assessments:-}

Enrolled participants for whom written informed consent was obtained were included in the safety analyses. Any untoward medical occurrence in a patient or clinical investigation patient administered a pharmaceutical product and which does not necessarily have to have a causal relationship with a treatment is defined as adverse events (AE) while a serious adverse event (SAE) is any untoward medical occurrence at any dose of the drug resulted in death, was life threatening, required inpatient hospitalization or caused a prolongation of an existing hospitalization. Severity and seriousness of AEs were determined solely under the discretion of the study investigators. All adverse events were reported in compliance with the applicable regulation and local guidelines.

\section{Ethical considerations:-}

This study was conducted in accordance with the principles established in by the $18^{\text {th }}$ World Medical Assembly (Helsinki, 1964) including all subsequent amendments, local laws and regulation, as well as the ICH guidelines for good clinical practice and Good Epidemiological Practice. Recruitment only commenced following IRB/IEC review and approval/favorable opinion. Written informed consent was obtained from all participants involved in this investigation prior to the conduct of any study-related activities.

\section{Statistical considerations:-}

The safety population included all patients who had signed an informed consent form. Patients in the eligible population (i.e. those satisfying all inclusion/exclusion criteria) were included in the baseline descriptive analyses. Of those, patients who had not committed any major protocol violations and had evaluable primary endpoint were included in the efficacy analyses.

Descriptive summary statistics were provided for quantitative data, and were summarized using count, mean with 95\% confidence interval (CI), standard deviation (SD), median, minimum, and maximum. The paired dependent $\mathrm{t}$ - 
test was employed to assess changes in mean HbA1c and weight during the study period. For comparisons involving patients who did achieved glycemic control to those who had not - including age, BMI, disease duration, and baseline glucose metrics - the student t-test was used for metric variables while the $\chi 2$ test was utilized for categorical variables. Binary logistic regression analyses were used to identify potential factors that may be predictive of glycemic control target. Repeated measures ANOVA on the other hand were used to assess longitudinal changes in insulin dose and weight throughout the study period. All statistical tests were performed at a $5 \%$ level of significance and using SPSS version 18.

\section{Results:-}

\section{Patient demographics:-}

In total, 1196 type 2 diabetic patients were recruited. Of those, eight were deemed ineligible due to a lack of inclusion/exclusion criteria fulfilment; were not prescribed basal or pre-mixed insulin at baseline. The remaining 1188 patients were eligible for enrollment and constituted the descriptive cohort (Figure 1). A summary of patients' demographics is shown in Table 1. Subjects in this cohort were evenly distributed in regards to gender $(55.5 \%$ males) with a mean age and BMI of $56.2 \pm 12.0$ years and $29.8 \pm 5.2 \mathrm{~kg} / \mathrm{m}^{2}$, respectively. The majority of subjects were of Arab ethnicity $(\mathrm{n}=908 ; 76.4 \%)$. Furthermore, most resided in urban environments $(\mathrm{n}=876 ; 73.7 \%)$, were married $(n=1063 ; 89.5 \%)$, employed $(n=667 ; 56.1 \%)$, and had basic/secondary education $(n=805 ; 67.8 \%)$. While the majority of subjects reported negative smoking histories $(\mathrm{n}=700 ; 58.8 \%)$, a considerable proportion had a history of smoking $(\mathrm{n}=247 ; 20.8 \%)$ and about one fifth were actively smoking $(\mathrm{n}=241 ; 20.3 \%)$. Additionally, most subjects did not regularly exercise $(n=881 ; 78.4 \%)$ or follow healthy diet plans $(n=617 ; 56.5 \%)$.

\section{Baseline disease characteristics:-}

Our patient population presented with a mean diabetes duration of $11 \pm 6.9$ years, and the majority were aware of a family history of diabetes $(n=932 ; 78.6 \%$; Table 2$)$. At baseline, blood glucose metrics at baseline - including FPG and PPG - were $208 \pm 68.5 \mathrm{mg} / \mathrm{dL}$ and $259.4 \pm 75.4 \mathrm{mg} / \mathrm{dL}$, respectively. The mean HbA1c for this cohort at baseline was $9.7 \pm 1.6 \%$, with a maximum and minimum of $16 \%$ and $7 \%$, respectively. A sizeable proportion of our participants had co-morbid hypertension $(n=682 ; 57.5 \%)$, most of whom were managed with anti-hypertensives $(n$ $=656 ; 96.2 \%)$. Many of our participants were afflicted with diabetes-related complications, the most common of those being sensory neuropathies $(n=427 ; 35.9 \%)$, microalbuminuria $(n=327 ; 27.5 \%)$, and retinopathies $(n=249$; $21.0 \%$ ).

\section{Pre-baseline management of disease:-}

Within a 12-month period prior to enrollment our subjects, on average, reportedly visited their treating physician $2.96 \pm 2.28$ times. Two third of patients $(\mathrm{n}=793 ; 66.8 \%)$ regularly self-monitored their blood glucose levels; 199 (25.6\%) performed the test daily, $234(30.1 \%)$ performed it at least once every three days, $239(30.7 \%)$ at least once a week, and $101(14.1 \%)$ at least once a month.

Only 46 (3.9\%) patients were registered with diabetic associations. Additionally, 156 (13.1\%) of participants reportedly referred to online educational material to further learn about their disease as well as management recommendations. In total, just over one third of patients $(n=469 ; 39.5 \%)$ received at least one form of diabetes education since their diagnosis.

Of the 1188 eligible patients, 1139 (95.9\%) were treated with oral anti-diabetic (OAD) medications (Table 3). The most commonly used OADs were sulfonylureas (SU) and Biguanides constituting 62.0\% ( $\mathrm{n}=706)$ and $61.2 \%$ $(\mathrm{n}=697)$ respectively following this treatment. A total of $421(37.0 \%)$ were receiving fixed dose combinations, including vildagliptin/metformin $(n=162 ; 38.5 \%)$, sitagliptin/metformin $(n=132 ; 31.4 \%)$, SU/metformin $(n=104$; $24.7 \%)$, and SU/TZD $(\mathrm{n}=2 ; 0.5 \%)$. Two thirds of subjects $(\mathrm{n}=805 ; 67.8 \%)$ were insulin naïve at baseline whilst $32.2 \%$ of participants $(n=383)$ had received insulin therapy previously including basal insulins $(n=245 ; 64.0 \%)$, premixed insulins $(\mathrm{n}=105 ; 27.4 \%)$, and prandial insulin $(\mathrm{n}=71 ; 18.5 \%)$.

\section{Allocation of treatment:-}

All 1088 eligible patient who participated in this current registry were prescribed basal insulin therapy at baseline visit, the majority of whom received insulin glargine $(n=1177 ; 99.1 \%$; Table 3). Basal insulin monotherapies were prescribed to 859 of the 1088 eligible subjects (72.3\%) for the management of HbA1c (Figure 2). The remainder of participants $(\mathrm{n}=329 ; 27.7 \%)$ received a combination of basal and prandial insulin. Prandial insulins that were 
prescribed included insulin glulisine $(n=247 ; 20.8 \%)$, insulin aspart $(\mathrm{n}=41 ; 3.5 \%)$, insulin lispro $(\mathrm{n}=29 ; 2.4 \%)$, and regular insulin $(\mathrm{n}=12 ; 1.0 \%)$.

Provided that the majority of patients $(67.8 \%)$ were not managed with insulin prior to enrollment, we explored the justification for adding insulin therapy at baseline. For the most part, add-on insulin therapy was prescribed because pre-baseline treatments did not adequately correct $\mathrm{HbA1c}(\mathrm{n}=1169 ; 98.4 \%)$. Other reasons included: 1) target fasting plasma glucose value not achieved $(\mathrm{n}=828 ; 69.7 \%) ; 2)$ target postprandial plasma glucose value not achieved $(\mathrm{n}=551 ; 46.4 \%) ; 3)$ worsening of pre-existing diabetes-related complication $(\mathrm{n}=125 ; 10.5 \%) ; 4)$ development of new diabetes-related complications $(n=124 ; 10.4 \%) ; 5)$ weight gain $(n=84 ; 7.1 \%)$; and 6$)$ hypoglycemic events $(n=63 ; 5.3 \%)$.

Primary endpoint:- change in HbAlc levels

The analysis population included all eligible subjects with an $\mathrm{HbA1c}$ value at the study endpoint (6 months), and for whom no protocol violations were committed $(\mathrm{n}=1083)$. For this population, a mean $9.8 \pm 1.6 \% \mathrm{HbAlc}$ was reported at baseline visit, with minimum and maximum values of $7 \%$ and $15.9 \%$. At the three-month follow up visit, mean $\mathrm{HbA1c}$ had significantly dropped by $1.5 \pm 1.4 \%$ to reach $8.2 \pm 1.2 \%$; with a $14.2 \% \pm 11.7 \%$ percent reduction $(\mathrm{p}<0.001)$. Furthermore, mean HbA1c dropped significantly by the 6-month follow up visit to $7.6 \pm 1.0 \%$ with a mean change of $2.2 \pm 1.5 \%$ when compared to baseline with a percentage reduction of $21.1 \% \pm 12.3 \%$; $p<0.001$. (Figure 3A)

\section{Secondary endpoint: achievement of glycemic control and predictive factors:-}

For the 977 subjects for whom a visit $2 \mathrm{HbA1c}$ values were collected, $74(7.6 \%)$ achieved the target, defined as HbA1c $<7 \%$. By study end, the number of patients achieving this desired goal rose to 280 (25.9\%); the majority of participants $(\mathrm{n}=803 ; 74.1 \%)$ did not meet their therapeutic goal following a 6-month treatment regimen (Figure 4). We compared subjects who had achieved the desired HbA1c target to those who had not in order to identify factors that may be predictive of glycemic control (Table 4). Our analyses revealed significant differences for the following factors: 1) age ( $=0.001)$; 2) BMI ( < 0.001); 3) HbA1c (p < 0.001); 4) FPG (p < 0.001); and 5) PPG (p < 0.001). Moreover, binary logistic regression models were run to identify factors that are potentially predictive of glycemic control and response to insulin treatment. As per our analyses, statistically significant associations were identified for higher age $(\mathrm{OR}=1.01 ; 95 \%$; CI: 1.00-1.03; $\mathrm{p}=0.043)$, lower BMI $(\mathrm{OR}=0.96$; 95\%; CI: 0.92-0.99; $\mathrm{p}=0.012)$, lower baseline HbA1c $(\mathrm{OR}=0.68$; 95\%CI: 0.59-0.78; $\mathrm{p}<0.001)$ as well as following an exercise plan $(\mathrm{OR}=1.49$; 95\% CI: 1.03-2.17; $\mathrm{p}=0.036$ ). Conversely, no significant associations between glycemic control and both baseline FBG $(\mathrm{p}=0.307)$ and following a healthy diet $(\mathrm{p}=0.492)$ were identified after controlling for other potential factors.

\section{Secondary endpoint: insulin titration:-}

At baseline, the mean basal insulin dose for our participants was $21.7 \pm 14.2 \mathrm{IU} / \mathrm{day}$, with a mean daily IU $/ \mathrm{kg}$ of 0.3 \pm 0.2 (Table 5). At the 3-month follow up visit, the mean insulin dose was significantly increased to $26.5 \pm 14.6$ IU/day $(\mathrm{p}<0.001)$ with a mean daily IU/kg of $0.3 \pm 0.2$. This significant increase continued up to study end; by month 6 the mean insulin dose was $28.2 \pm 14.4$ IU/day with a mean daily IU $/ \mathrm{kg}$ of $0.4 \pm 0.2(\mathrm{p}<0.001)$.

For participants for whom insulin glargine was prescribed, the starting mean daily dose was $21.7 \pm 14.0 \mathrm{IU} /$ day at baseline with a corresponding IU/kg of $0.3 \pm 0.2$. Further increases in the mean prescribed dose were observed at month 3 and 6; the reported glargine insulin dose was $26.5 \pm 14.3 \mathrm{IU} /$ day $(0.3 \pm 0.2 \mathrm{IU} / \mathrm{kg})$ and $28.1 \pm 14.2 \mathrm{IU} / \mathrm{day}$ $(0.4 \pm 0.2 \mathrm{IU} / \mathrm{kg})$ at visits 2 and 3 , respectively (Table 5).

\section{Secondary endpoint: change in weight:-}

No clinically or statistically notable changes in mean weight were observed throughout the study period (Table 5). A marginal increase in mean weight was observed for enrolled participants at month $3(82.9 \pm 14.5 \mathrm{Kg}$ from 82.8 $\pm 14.4 \mathrm{Kg} ; \mathrm{p}=0.555)$. Following six months of treatment, mean weight reached a nadir of $82.6 \pm 14.1(\mathrm{p}=0.211)$.

\section{Exploratory endpoint: change in FPG and PPG:-}

At month 3, mean FPG declined to $148.1 \pm 41.5 \mathrm{mg} / \mathrm{dL}$ from a baseline of $208.1 \pm 70 \mathrm{mg} / \mathrm{dL}$; a significant $24.5 \% \pm$ $22.4 \%$ reduction ( $<$ 0.001; Figure 3B). FPG continued this downward trend and reached a low of $128.6 \pm 32.3$ $\mathrm{mg} / \mathrm{dL}$ by study end, marking a $32.9 \% \pm 26.2 \%$ reduction compared to baseline $(\mathrm{p}<0.001)$. As with FPG, significant reductions in PPG were also observed throughout the duration of the registry. At month 3, mean PPG 
dropped significantly by $25.2 \% \pm 21.7 \%$, from $259.6 \pm 74.4 \mathrm{mg} / \mathrm{dL}$ to $187.7 \pm 46.5 \mathrm{mg} / \mathrm{dL}$ (p < 0.001 ). By study end, enrolled patients exhibited a further significant drop in mean PPG, reaching a low of $167.5 \pm 43.5 \mathrm{mg} / \mathrm{dl}$ at month $6(31.3 \% \pm 24.4 \%$ reduction; $\mathrm{p}<0.001)$.

\section{Safety and tolerability $(\mathrm{N}=1196)$ :-}

Safety analysis was performed on the total population enrolled to the study. A combined total of 68 hypoglycemia events were reported by $63(5.3 \%)$ patients (0.06 events/patient). This included 50 documented hypoglycemia events for $46(3.8 \%)$ participants (0.04 events/patient; Table 6), and 18 probable symptomatic hypoglycemia events reported for $17(1.4 \%)$ patients (0.02 events/patient). Among the patients who had experienced events of documented hypoglycemia, two $(0.2 \%)$ required assistance. None of our participants experienced loss of consciousness/coma, seizures nor admission to emergency department due to a hypoglycemic episode. Oral carbohydrates were administered to affected patients for all 50 events, and this led to a restoration of blood glucose and a complete recovery. As for probable hypoglycemia events, none of the events led to loss of consciousness/coma, seizures, admission to emergency department nor required assistance. For all these cases, oral carbohydrates were successfully used to recover affected patients. Regarding adverse events other than hypoglycemia, a total of $22(1.8 \%)$ adverse events were experienced by $21(1.8 \%)$ patients during the 6 months of study. Of those, $11(0.9 \%)$ were non-serious and $11(0.9 \%)$ was serious.

\section{Discussion:-}

For this non-interventional, non-controlled, and observational prospective product registry, we set out to primarily evaluate the effectiveness of insulin therapies in "real-world" clinical settings. We also aimed to assess the incidence of hypoglycemia associated with the use of such therapies, as well as determine potential factors that are predictive of treatment response. The major observations from this registry included the following: 1) prior to enrollment, Two third of participants were managed solely with OAD treatments; 2) basal insulin monotherapy was the primary treatment of choice among participating physicians and centers; 3) T2D patients exhibited significant improvements in HbA1c, FPG, and PPG; 4) no significant weight gain was observed in patients receiving insulin treatment; and 5) the hypoglycemic event rate was minimal.

Comprehensive glycemic control in patients with a shorter diabetes mellitus duration drastically reduces the risk of cardiovascular complications and improves both the macrovascular and microvascular prognosis (Le Floch, 2010, Skyler et al., 2009). To ensure a restoration of glycemic homeostasis and minimize the effects of chronic glucotoxicity, the ADA advocates the institution of insulin-based therapies at early stages of the disease for patients who are symptomatic and/or exhibit an $\mathrm{HbA1c} \geq 10 \%{ }^{9}$ In this registry - and consistent with previous reports - the majority of participants were previously managed with OAD therapies alone (Sorli and Heile 2014). This is of particular interest considering the elevated baseline HbAlc $(9.74 \%)$ in our cohort, as well as the extended disease duration that was observed at baseline $(11 \pm 6.9$ years $)$. The reluctance to initiate insulin-based therapy is as a considerable challenge to T2D treatment, and has been attributed to clinician- and patient-centric factors including clinical inertia, fears of hypoglycemia and weight gain, the perceived complexity and inconvenience of insulin therapy, as well as cost concerns (Sorli and Heile 2014).

In our investigation, we observed a relatively high incidence of disease-related complications in patients afflicted with type 2 diabetes; over half of participants presented with various diabetes-related complications, and chief among them was sensory neuropathy. This observation was consistent with reports from previous investigations, and is unsurprising since multiple pathophysiological abnormalities are associated with insulin resistance and progressive $\beta$-cell dysfunction (Deshepande et al., 2008, Gregg et al., 2004, Adler et al., 1997). This prevalence of diabetes-related complications reveals the potential burden of T2D on healthcare systems and societies, and further emphasizes the need to develop treatments and management strategies that effectively prevent, delay, or promptly re-establish glycemic control to minimize the risk of comorbidities in those affected (Pagano et al., 1999, Clarke et al., 2003).

In everyday clinical practice, inadequately controlled T2D patients benefit from treatment with basal insulins. In this current registry, $25.9 \%$ of patients receiving insulin-based therapies for a six-month period achieved normoglycemic status. Utilization of basal insulin led to a $21.1 \%$ reduction in HbA1c from a baseline of $9.8 \%$. These observations, as well as the reported improvements in FPG (-32.9\% from $208.1 \mathrm{mg} / \mathrm{dL})$ and PPBG (-31.3\% from 259.6 mg/dL), are consistent with data from previous trials, and cement the notion that insulin-based therapies facilitate the achievement of glycemic control in T2D patients (Schreiber and Haak, 2007, Riddle, Rosenstock, and Gerich 2007, 
Rosenstock et al., 2001). The daily dose of basal insulin by study end was titrated up to a mean of 28.2 IU from 21.7 IU. Whilst this reported dose is in agreement with previous studies, it is interesting to note that Schreiber et al. (2007) were able to achieve glycemic control with a lower insulin dose (Fritsche et al., 2003, 25. Yki-Järvinen 2002). This higher dose of insulin that was required to achieve glycemic control might be an artefact of the long disease duration in our cohort (Schreiber and Haak, 2007).

Lower baseline HbA1c was associated with an increased likelihood of treatment success $(\mathrm{OR}=0.68$; $\mathrm{p}<0.001)$. This observation is of important clinical significance, further emphasizing the importance of initiating insulin earlier during the disease process as opposed to reserving such treatments as a last resort when glycemic control has worsened. Additionally, and consistent with other reports was the association of glycemic control with both BMI $(O R=0.96 ; p=0.012)$ and exercise $(O R=0.96 ; p=0.012)$. Our observations indicate that antidiabetic treatments are just one facet of T2D management, and those intensive lifestyle interventions that involve increased physical activity to reduce weight increase the likelihood of treatment success (Hamman, 2006).

Much of the clinical inertia among healthcare providers for insulin treatment initiation or optimization is attributable to concerns about hypoglycemia and weight gain (Korytkowski, 2002, Johnson et al., 2003, Janka et al., 2005). On the basis of this observational study, treatment with insulin-based therapies improves glycemic control without an increase in hypoglycemic events. We noted a markedly lower incidence of documented or confirmed hypoglycemia at 6 months when compared to 3 months before baseline $(n=46 ; 3.8 \%$ vs. $n=65 ; 5.7 \%)$. Furthermore, no clinically significant changes in weight were observed; mean weight of participants decreased to $82.6 \mathrm{~kg}$ from $82.8 \mathrm{~kg}$. Our observations are consistent with those reported in previously conducted, large-scale observational studies and indicate that insulin-based therapies are associated with a lower incidence of hypoglycemia and undesirable gain in weight (Schreiber and Haak, 2007).

There are several limitations to the current study that should be noted. Given the observational nature of this investigation, the lack of a control arm means it is difficult to effectively assess the efficacy and safety of basal insulin therapy for T2D. Furthermore, it is well established that T2D patients, once recruited to a clinical trial, may exhibit HbA1c improvements, independent of any therapeutic intervention, due to the "observer effect" phenomenon which may further compound our findings (Gale et al., 2007). It should also be noted that assessment of treatment adherence was beyond the scope of this investigation. According to recent surveys and reports, about half of T2D patients do not achieve adequate glycemic control (Polonsky and Henry, 2016, Ali et al., 2012, Ford 2011). While this apparent failure to achieve treatment-goals has been accredited to several factors, a lack of treatment adherence is certainly a chief contributor. Poor treatment adherence is a persistent issue that affects more than one half of the T2D population, and can incur significant health and economic burdens including inadequate glycemic control, higher medical cost of treatment, increased use of healthcare resources, and higher mortality rates (Egede et al., 2014a, Egede et al., 2012b, DiBonaventura, 2014). A multifaceted approach that encompasses educational sessions, treatment simplification, motivational strategies, medication reminders, and special packaging can potentially improve treatment adherence, and as a result, treatment outcomes (Sapkota et al., 2015).

In Conclusions, despite these limitations, we believe that the observations made in this study should not be understated as they provide a representative report of the effectiveness of insulin-based therapies in real-world clinical settings. This multinational, multicenter product registry demonstrated statistically and clinically significant reductions in FBG, PPBG, and HbA1c levels following treatment with basal insulin glargine with or without a prandial insulin. Hypoglycemia event rate was minimal and no notable changes in weight were observed. Glycemic improvements were more pronounced in patients with lower baseline HbA1c and BMI, as well as patients that follow an exercise plan. Basal insulin with or without a prandial insulin is a safe, efficacious, and convenient treatment alternative for patients failing to achieve optimal glycemic control with conventional OAD therapy.

\section{Acknowledgments:-}

This study was funded by Sanofi-Aventis UAE. Editorial support for this article was provided by Mohamad Taha, Kareem El Iskandrani and Omnia Aboutaleb on behalf of DataClin CRO.

Sanofi was responsible for study design, provided overall trial management, and provided a formal review of the publication. DataClin performed the statistical analysis and verified the accuracy of the data. The authors interpreted the data and had final authority including journal choice. 
This investigation was conducted by investigators in the UAE, Kuwait, Qatar, Bahrain, and Lebanon. We thank all participating centers for their valuable involvement in this study.

Ali Al-Slani, Aly Shaheen, Abdulatif Alkutabi, Afshin Sadeghiyan, Ahmed M. Yahyen, Ahmed Qatabi, Amal Sharkawi, Amgad Edward, Ashraf Hassanein Zaki, Assad Al-Dafter, Atef Nassef, Emad Abd El-Wahed, Essam AlName, George Samir, Hadiah Azzam Kayiaseh, Hanan Hassan, Hasan Ahmed Mohamed Hassan, Hesham Mohammady, Hisham Al-Sayed, Hosam Al-Ghusain, Khaled Said Galil, Laxmi Kant Sharma, Leena Kapoor, Maged Abu Shamaa, Mathew Abraham, Mohamad Ashraf, Mohamed Jawad, Moustafa Sayed Abdel Aziz, Mustafa Rabii, Nagi Lewis, Nand Kishore, Omar Mashhor, Oussama Kneina, Rajagopalan Chelanat, Rajendra Babu, Rakesh Kumar, Rameshan Parinneth, Reyaz Ahmad, Saleh Homoud, Salwa Mabrouk, Sameem Matto, Sarla Kumari, Shabeer Abdul Mohammed, Srinivasa Rao Polumuru, Tarek Abd El-Hamid, Waafa Al-Kamali, Wafeeq Saba, Wassim Mahamoud A. Hassan and Yasmine Ajaz.

Disclosure of conflict of interest:-

The authors have no conflicts of interest to declare.

\begin{tabular}{|l|l|}
\hline Figure 1 & Patient disposition \\
\hline Figure 2 & Allocation of treatment \\
\hline Figure 3 & Improvement in HbA1c and FBG following initiation/adjustment of insulin-based treatments \\
& during the study period. \\
& $\# p<0.001$ \\
& $* \mathrm{p}<0.001$ \\
\hline Figure 4 & $\%$ Achieved target HbA1c $(7 \%)$ \\
\hline
\end{tabular}

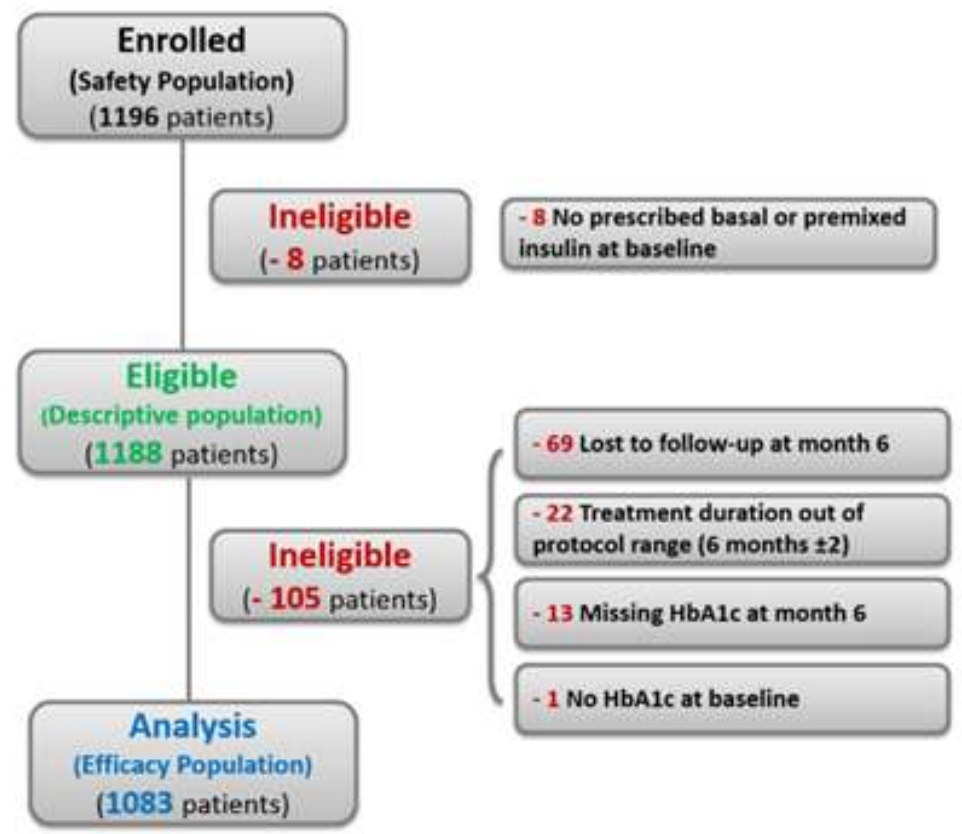




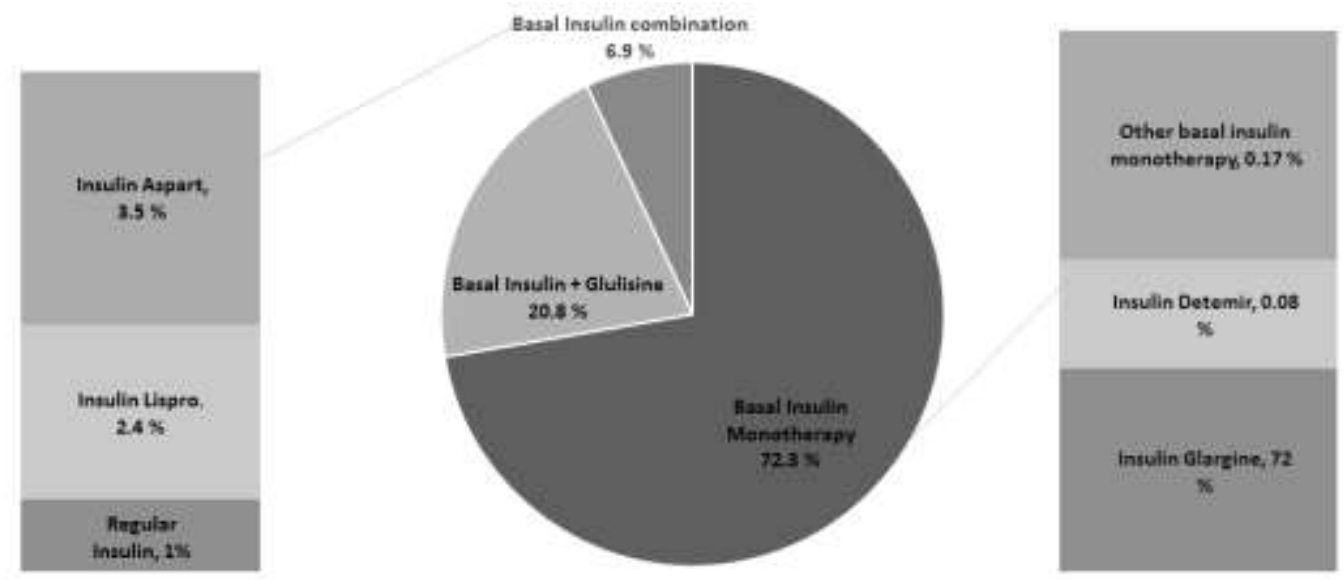

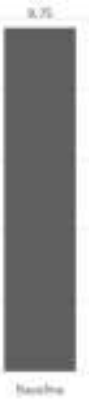

(A)

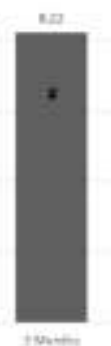

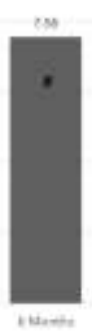

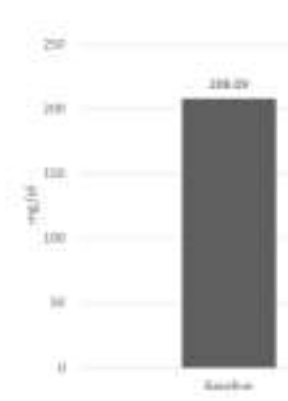

inctis
(B)

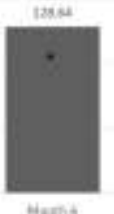

tivents

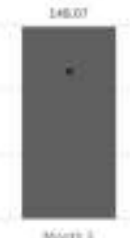

Change in FBG during the stuby period

$\%$ Achieved target $\mathrm{HbA} 1 \mathrm{c}(<7 \%)$

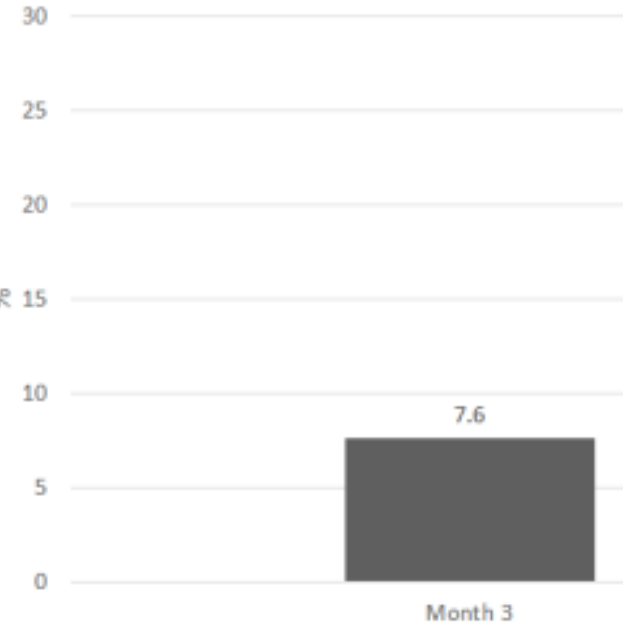

25.9

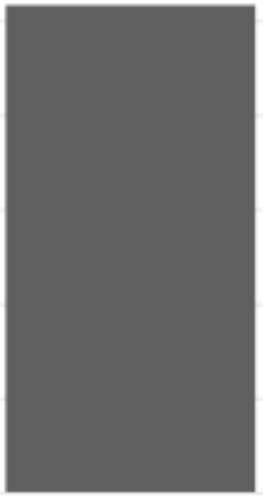

Month 6 
Table 1:- Patient demographics

\begin{tabular}{|c|c|}
\hline Demographic data & Mean \pm SD/Count $(\%)$ \\
\hline \multicolumn{2}{|c|}{ Demographics } \\
\hline \multicolumn{2}{|l|}{ Gender: } \\
\hline - Male & $659(55.5)$ \\
\hline Age (years) & $56.24 \pm 11.99 *$ \\
\hline Weight (kg) & $82.66 \pm 14.87 \#$ \\
\hline Height $(\mathrm{cm})$ & $166.67 \pm 8.85^{\Phi}$ \\
\hline BMI $\left(\mathrm{kg} / \mathrm{m}^{2}\right)$ & $29.80 \pm 5.23$ \\
\hline \multicolumn{2}{|l|}{ Race/Ethnicity: } \\
\hline - Arab & $908(76.4)$ \\
\hline - Asian & $209(17.6)$ \\
\hline - Caucasian & $61(5.1)$ \\
\hline - Black & $6(0.5)$ \\
\hline - Other & $4(0.3)$ \\
\hline \multicolumn{2}{|c|}{ Lifestyle } \\
\hline \multicolumn{2}{|l|}{ Smoking history: } \\
\hline - Never smoker & $700(58.8)$ \\
\hline - Previous smoker & $247(20.8)$ \\
\hline - Current smoker & $241(20.3)$ \\
\hline \multicolumn{2}{|l|}{ Regularly Exercise? } \\
\hline - No & $881(78.4)$ \\
\hline \multicolumn{2}{|l|}{ Eat healthy? } \\
\hline - Yes & $475(43.5)$ \\
\hline \multicolumn{2}{|c|}{ Marital Status } \\
\hline Married & $1063(89.5)$ \\
\hline Single & $86(7.2)$ \\
\hline Divorced/widowed & $39(3.3)$ \\
\hline \multicolumn{2}{|c|}{ Education } \\
\hline Basic/elementary & $409(34.4)$ \\
\hline Secondary & $396(33.3)$ \\
\hline Higher education (university) & $284(23.9)$ \\
\hline None & $99(8.3)$ \\
\hline \multicolumn{2}{|c|}{ Employment } \\
\hline Employed & $667(56.1)$ \\
\hline Unemployed & $521(43.9)$ \\
\hline - Due to diabetes & $8(0.7)$ \\
\hline \multicolumn{2}{|c|}{ Residence } \\
\hline Urban & $876(73.7)$ \\
\hline Rural & $312(26.3)$ \\
\hline $\begin{array}{l}* \text { Age not recorded for } 2 \text { patients } \\
\text { \# Weight was not recorded for } 1 \text { patient } \\
\phi \text { Height was not recorded for } 14 \text { patients }\end{array}$ & \\
\hline
\end{tabular}

Table 2:- Baseline and disease characteristics

\begin{tabular}{|c|c|}
\hline \multicolumn{1}{|c|}{ Characteristic } & Mean \pm SD/Count (\%) \\
\hline \multicolumn{2}{|c|}{ Vital Signs } \\
\hline Blood pressure (mmHg): & $132.18 \pm 13.74$ \\
\hline Systolic & $80.15 \pm 8.84$ \\
\hline Diastolic & $79.64 \pm 8.43$ \\
\hline Pulse rate (beats/min) & $10.96 \pm 6.89$ \\
\hline \multicolumn{2}{|c|}{ Disease Characteristics } \\
\hline Disease duration (years) & \\
\hline
\end{tabular}




\begin{tabular}{|l|c|}
\hline Family history of diabetes & $932(78.6)$ \\
\hline FPG $(\mathrm{mg} / \mathrm{dL})$ & $207.97 \pm 68.52$ \\
\hline PPG $(\mathrm{mg} / \mathrm{dL})$ & $259.36 \pm 75.36$ \\
\hline HbA1c $(\%)$ & $9.74 \pm 1.63$ \\
\hline - Min/Max & $7 / 16$ \\
\hline Dyslipidemia & $752(66)$ \\
\hline Hypertension & $682(57.5)$ \\
\hline - Receiving anti-hypertensive & $656(96.2)$ \\
\hline Absent & $513(43.2)$ \\
\hline Present & $675(56.8)$ \\
\hline - Sensory Neuropathy & $427(35.9)$ \\
\hline - Microalbuminuria & $327(27.5)$ \\
\hline - Retinopathy & $249(21.0)$ \\
\hline - Peripheral Vascular Disease & $76(6.4)$ \\
\hline - Proteinuria & $71(6.0)$ \\
\hline - History of revascularization & $70(5.9)$ \\
\hline - Myocardial Infarction/Acute Coronary Syndrome & $63(5.3)$ \\
\hline - Rengina & $60(5.1)$ \\
\hline - Foot ulcer & $57(4.8)$ \\
\hline - Amputation & $35(2.9)$ \\
\hline - Heart Failure & $5(0.4)$ \\
\hline - Dialysis & $25(2.1)$ \\
\hline - Stroke & $2(0.2)$ \\
\hline & $29(2.4)$ \\
\hline
\end{tabular}

Table 3:- Pre-enrollment diabetes management

\begin{tabular}{|c|c|}
\hline Intervention & Mean \pm SD/Count $(\%)$ \\
\hline \multicolumn{2}{|c|}{ Education } \\
\hline \multicolumn{2}{|l|}{ Member of diabetes association? } \\
\hline - Yes & $46(3.9)$ \\
\hline \multicolumn{2}{|l|}{ Utilize online educational sources? } \\
\hline - Yes & $156(13.1)$ \\
\hline \multicolumn{2}{|l|}{ Received any diabetes-related education? } \\
\hline - Yes & $469(39.5)$ \\
\hline \multicolumn{2}{|c|}{ Glucose self-monitoring } \\
\hline \multicolumn{2}{|l|}{ Perform blood glucose self-monitoring? } \\
\hline - Yes & $919(77.4)$ \\
\hline \multicolumn{2}{|c|}{ Prior Antidiabetic Interventions } \\
\hline Oral antidiabetics & $1139(95.9)$ \\
\hline - Sulfonyureas & $706(62.0)$ \\
\hline - Biguanides & $697(61.2)$ \\
\hline - Depeptidyl peptidase 4 inhibitors (DPP-4) & $295(25.9)$ \\
\hline - $\quad$ Thiazolidinediones & $64(5.6)$ \\
\hline - Glinides & $29(2.6)$ \\
\hline - Sodium-glucose co-transporter 2 (SGLT2) & $15(1.3)$ \\
\hline - Alpha-glucosidase inhibitor & $11(1.0)$ \\
\hline Fixed-dose combinations & $421(37.0)$ \\
\hline - Vildagliptin + metformin & $162(38.5)$ \\
\hline - Sitagliptin + Metformin & $132(31.4)$ \\
\hline - Sulfonyureas + Metformin & $104(24.7)$ \\
\hline - Sulfonyureas + Thiazolidinedione & $2(0.5)$ \\
\hline - Saxgliptin + Metformin & $13(3.1)$ \\
\hline
\end{tabular}




\begin{tabular}{|c|c|}
\hline - DPP-4 + Metformin & $2(0.5)$ \\
\hline Linagliptin + metformin & $2(0.5)$ \\
\hline - DPP-4 + Sulfonyureas & $1(0.2)$ \\
\hline Insulin & $383(32.2)$ \\
\hline - Basal insulin & $121(31.6)$ \\
\hline - Prandial insulin & $71(18.5)$ \\
\hline - Premixed insulin & $105(27.4)$ \\
\hline \multicolumn{2}{|c|}{ Prescribed Insulin-Based Interventions at Baseline } \\
\hline Basal insulin alone & $859(72.3)$ \\
\hline Basal + prandial insulins & $329(27.7)$ \\
\hline
\end{tabular}

Table 4:- Predictors of glycemic control

\begin{tabular}{|l|c|c|c|}
\hline Predictive factors & $\begin{array}{c}\text { Achieved } \\
\text { Mean } \pm \text { SD }\end{array}$ & $\begin{array}{c}\text { Not achieved } \\
\text { Mean } \pm \text { SD }\end{array}$ & P value \\
\hline Age $(\mathrm{y})$ & $58.13 \pm 11.81$ & $55.35 \pm 11.80$ & 0.001 \\
\hline BMI $\left(\mathrm{kg} / \mathrm{m}^{2}\right)$ & $28.73 \pm 4.31$ & $30.24 \pm 5.33$ & $<0.001$ \\
\hline T2D duration $(\mathrm{y})$ & $10.47 \pm 6.72$ & $11.05 \pm 6.78$ & 0.223 \\
\hline Baseline HbA1c $(\%)$ & $9.13 \pm 1.47$ & $9.96 \pm 1.61$ & $<0.001$ \\
\hline Baseline FPG $(\mathrm{mg} / \mathrm{dL})$ & $197.08 \pm 61.08$ & $212.10 \pm 68.63$ & 0.001 \\
\hline Baseline PPG $(\mathrm{mg} / \mathrm{dL})$ & $238.76 \pm 62.28$ & $266.92 \pm 76.85$ & $<0.001$ \\
\hline
\end{tabular}

BMI body mass index; HbA1c glycated hemoglobin; FPG fasting plasma glucose; PPG postprandial plasma glucose

Table 5:- Changes in insulin dose and weight

\begin{tabular}{|c|c|c|c|}
\hline $\begin{array}{c}\text { Basal Insulin Dose } \\
\text { (IU/day) }\end{array}$ & Baseline & Month 3 & Month 6 \\
\hline Mean \pm SD & $21.74 \pm 14.15$ & $26.54 \pm 14.55$ & $28.19 \pm 14.44$ \\
\hline$\%$ change & $-/-$ & $33.61 \pm 54.55$ & $45.15 \pm 67.35$ \\
\hline p Value & $-/-$ & $\mathrm{p}<0.001$ & $\mathrm{p}<0.001$ \\
\hline Mean U/kg & $0.27 \pm 0.17$ & $0.32 \pm 0.17$ & $0.35 \pm 0.17$ \\
\hline p Value & $-/-$ & $\mathrm{p}<0.001$ & $\mathrm{p}<0.001$ \\
\hline $\begin{array}{c}\text { Insulin Glargine Dose } \\
\text { (IU/day) }\end{array}$ & Baseline & Month 3 & Month 6 \\
\hline Mean \pm SD & $21.67 \pm 14.02$ & $26.49 \pm 14.28$ & $28.09 \pm 14.20$ \\
\hline p Value & $-/-$ & $p=0.527$ & $\mathrm{p}<0.05$ \\
\hline Mean IU/kg & $0.27 \pm 0.17$ & $0.32 \pm 0.17$ & $0.35 \pm 0.17$ \\
\hline Weight (Kg) & Baseline & Month 3 & Month 6 \\
\hline Mean \pm SD & $82.79 \pm 14.42$ & $82.86 \pm 14.48$ & $82.56 \pm 14.11$ \\
\hline $\mathrm{p}$ Value & $-/-$ & $\mathrm{p}<0.555$ & $\mathrm{p}<0.211$ \\
\hline
\end{tabular}

Table 6:- Incidence of hypoglycemic events

\begin{tabular}{|c|c|c|c|}
\hline \multirow{2}{*}{$\begin{array}{l}\text { Treatment } \\
\text { period }\end{array}$} & \multicolumn{3}{|c|}{ Patients experiencing treatment-induced hypoglycemic events } \\
\hline & Documented & Probable & Total \\
\hline $\mathrm{N}(\%)$ & $46(3.8 \%)$ & $17(1.4 \%)$ & $63(5.3 \%)$ \\
\hline
\end{tabular}

\section{References:-}

1. Murray CJ, Barber RM, Foreman KJ, Ozgoren AA, Abd-Allah F, Abera SF, Aboyans V, Abraham JP, Abubakar I, Abu-Raddad LJ, Abu-Rmeileh NM. Global, regional, and national disability-adjusted life years (DALYs) for 306 diseases and injuries and healthy life expectancy (HALE) for 188 countries, 1990-2013: quantifying the epidemiological transition. The Lancet. 2015 Dec 4;386(10009):2145-91.

2. World Health Organization. Global report on diabetes. World Health Organization; 2016. 
3. Wild S, Roglic G, Green A, et al. Global prevalence for diabetes. Estimates for the year 2000 and projections for 2030. Diabetes Care. 2004; 27(5):1047-53.

4. Majeed A, El-Sayed AA, Khoja T, Alshamsan R, Millett C, Rawaf S. Diabetes in the Middle-East and North Africa: an update. Diabetes research and clinical practice. 2014 Feb 28;103(2):218-22.

5. Zabetian A, Keli HM, Echouffo-Tcheugui JB, Narayan KV, Ali MK. Diabetes in the middle east and north Africa. Diabetes research and clinical practice. 2013 Aug 31;101(2):106-22.

6. DeFronzo RA. Pathogenesis of type 2 diabetes: Metabolic and molecular implications for identifying diabetes genes. Diabetes Res Clin Pract. 1997;5:177-269.

7. Stratton IM, Adler AI, Neil HA, Matthews DR, Manley SE, Cull CA, Hadden D, Turner RC, Holman RR. Association of glycaemia with macrovascular and microvascular complications of type 2 diabetes (UKPDS 35): prospective observational study. Bmj. 2000 Aug 12;321(7258):405-12.

8. American Diabetes Association. Standards of medical care in diabetes - 2017. Diabetes Care. 2017; 40 (Suppl. 1): $1-142$.

9. Hamaty M. Insulin treatment for type 2 diabetes: When to start, which to use. Cleve Clin J Med. 2011;78(5):332-342.

10. Pearson J, Powers MA. Systematically initiating insulin: the staged diabetes management approach. Diabetes Educ. 2006;32(1):19S-28S.

11. Sharplin P, Gordon J, Peters JR, Tetlow AP, Longman AJ, McEwan P. Switching from premixed insulin to glargine-based insulin regimen improves glycaemic control in patients with type 1 or type 2 diabetes: a retrospective primary care-based analysis. Cardiovascular diabetology. 2009 Feb 16;8(1):9.

12. Le Floch JP. Critical appraisal of the safety and efficacy of insulin detemir in glycemic control and cardiovascular risk management in diabetics. Diabetes, metabolic syndrome and obesity: targets and therapy. 2010;3:197.

13. Skyler JS, Bergenstal R, Bonow RO, Buse J, Deedwania P, Gale EA, Howard BV, Kirkman MS, Kosiborod M, Reaven P, Sherwin RS. Intensive glycemic control and the prevention of cardiovascular events: implications of the ACCORD, ADVANCE, and VA diabetes trials. Circulation. 2009 Jan 20;119(2):351-7.

14. Sorli C, Heile MK. Identifying and meeting the challenges of insulin therapy in type 2 diabetes. Journal of multidisciplinary healthcare. 2014;7:267.

15. Deshpande AD, Harris-Hayes M, Schootman M. Epidemiology of diabetes and diabetes-related complications. Physical therapy. 2008 Nov 1;88(11):1254-64.

16. Gregg EW, Sorlie P, Paulose-Ram R, Gu Q, Eberhardt MS, Wolz M, Burt V, Curtin L, Engelgau M, Geiss L. Prevalence of lower-extremity disease in the US adult population $\geq 40$ years of age with and without diabetes. Diabetes care. 2004 Jul 1;27(7):1591-7.

17. Adler AI, Boyko EJ, Ahroni JH, Stensel V, Forsberg RC, Smith DG. Risk factors for diabetic peripheral sensory neuropathy: results of the Seattle Prospective Diabetic Foot Study. Diabetes care. 1997 Jul 1;20(7):1162-7.

18. Pagano E, Brunetti M, Tediosi F, Garattini L. Costs of Diabetes. Pharmacoeconomics. 1999 Jun 1;15(6):583-95.

19. Clarke P, Gray A, Legood R, Briggs A, Holman R. The impact of diabetes-related complications on healthcare costs: results from the United Kingdom Prospective Diabetes Study (UKPDS Study No. 65). Diabetic Medicine. 2003 Jun 1;20(6):442-50.

20. Schreiber SA, Haak T. Insulin glargine benefits patients with type 2 diabetes inadequately controlled on oral antidiabetic treatment: an observational study of everyday practice in 12,216 patients. Diabetes, Obesity and Metabolism. 2007 Jan 1;9(1):31-8.

21. Riddle MC, Rosenstock J, Gerich J. The treat-to-target trial. Diabetes care. 2003 Nov 1;26(11):3080-6.

22. Rosenstock J, Schwartz SL, Clark CM, Park GD, Donley DW, Edwards MB. Basal insulin therapy in type 2 diabetes. Diabetes care. 2001 Apr 1;24(4):631-6.

23. Fritsche A, Schweitzer MA, Hring HU. Glimepiride Combined with Morning Insulin Glargine, Bedtime Neutral Protamine Hagedorn Insulin, or Bedtime Insulin Glargine in Patients with Type 2 DiabetesA Randomized, Controlled Trial. Annals of internal medicine. 2003 Jun 17;138(12):952-9.

24. Yki-Järvinen H. Combination therapy with insulin and oral agents: optimizing glycemic control in patients with type 2 diabetes mellitus. Diabetes/metabolism research and reviews. 2002 Sep 1;18(S3).

25. Hamman RF, Wing RR, Edelstein SL, Lachin JM, Bray GA, Delahanty L, Hoskin M, Kriska AM, Mayer-Davis EJ, Pi-Sunyer X, Regensteiner J. Effect of weight loss with lifestyle intervention on risk of diabetes. Diabetes care. 2006 Sep 1;29(9):2102-7.

26. Korytkowski M. When oral agents fail: practical barriers to starting insulin. International Journal of Obesity. 2002 Sep 1;26(S3):S18. 
27. Johnson R, Haubner B, Bolinder B. Trade-offs between glucose control and hypoglycemia in different patient types: results of a 5-country physician survey. Diabetes. 2003 Jun 1;52:A264.

28. Janka HU, Plewe G, Riddle MC, Kliebe-Frisch C, Schweitzer MA, Yki-Järvinen H. Comparison of basal insulin added to oral agents versus twice-daily premixed insulin as initial insulin therapy for type 2 diabetes. Diabetes care. 2005 Feb 1;28(2):254-9.

29. Gale EAM, Beattie SD, HU J, et al. Recruitment to a clinical trial improves glycemic control in patients with diabetes. Diabetes Care. 2007;30(12):2989-92.

30. Polonsky WH, Henry RR. Poor medication adherence in type 2 diabetes: recognizing the scope of the problem and its key contributors. Patient preference and adherence. 2016;10:1299.

31. Ali MK, Bullard KM, Imperatore G, Barker L, Gregg EW. Characteristics associated with poor glycemic control among adults with self-reported diagnosed diabetes-National Health and Nutrition Examination Survey, United States, 2007-2010. MMWR Morb Mortal Wkly Rep. 2012 Jun 15;61(2):32-7.

32. Ford ES. Trends in the control of risk factors for cardiovascular disease among adults with diagnosed diabetes: findings from the National Health and Nutrition Examination Survey 1999-2008. Journal of diabetes. 2011 Dec 1;3(4):337-47.

33. Egede LE, Gebregziabher M, Echols C, Lynch CP. Longitudinal effects of medication nonadherence on glycemic control. Annals of Pharmacotherapy. 2014 a May;48(5):562-70.

34. Egede LE, Gebregziabher M, Dismuke CE, Lynch CP, Axon RN, Zhao Y, Mauldin PD. Medication nonadherence in diabetes. Diabetes care. 2012b Dec 1;35(12):2533-9.

35. DiBonaventura M, Wintfeld N, Huang J, Goren A. The association between nonadherence and glycated hemoglobin among type 2 diabetes patients using basal insulin analogs. Patient preference and adherence. 2014;8:873.

36. Sapkota S, Jo-anne EB, Greenfield JR, Aslani P. A systematic review of interventions addressing adherence to anti-diabetic medications in patients with type 2 diabetes - components of interventions. PLoS One. 2015 Jun 8;10(6):e0128581. 